\title{
Fizz in the Field: Toward a Basis for an Emergent Internet Studies
}

Steve Jones

\section{QUERY SHEET}

Q1: Au: 191? 


\section{Fizz in the Field: Toward a Basis for an Emergent Internet Studies}

\section{Steve Jones}

Department of Communication, University of Illinois at Chicago, Chicago, Illinois, USA

5

\begin{abstract}
This article examines the history and future prospects of the formation of Internet studies. It is argued that although a traditional field or disciplinary structure is not yet in place, the current interdisciplinary aggregations may have the makings of institutionalized academic units. Through comparison with the institutionalization of other interdisiciplinary areas of study (primarily that of communication and cultural studies), an argument is made for the need to create a firm intellectual foundation on which an Internet/studies can be built. Such a foundation should not only include sufficient grounding of power (as theoretical construct and practice) as a means of engaging the field in the world.
\end{abstract}

Keywords academia, institutionalization, interdisciplinarity, Internet research, Internet studies

As I write this essay the tenth anniversary of the founding of the World Wide Web Consortium by Tim BernersLee has come and gone. It is 15 years since Berners-Lee first proposed the hypertext system that became the Web. It is 40 years since Paul Baran described packet-switching infrastructure. The scholarly study of computer-mediated communication (CMC) can be traced back at least as far if one considers the work at DARPA, RAND, and the University of Colifornia at Los Angeles (UCLA) as the earliest work in the field. Yet the Association of Internet Researchers is a scant 6 years old, and there is already debate about whether there is such a thing as a field of "Internet studies."

If there is a field, it is only by using the term in its broadest sense that we can fit an Internet studies to what

Received 27 February 2004; accepted 9 January 2005.

The author wishes to thank anonymous reviewers for very helpful suggestions.

Address correspondence to Steve Jones, Professor of Communication, University of Illinois at Chicago, 1007 W. Harrison (m/c 132), Chicago, IL 60607, USA. E-mail: sjones@uic.edu it means. It is only apparent by viewing the variety of centers, institutes, units, etc., the nascent degree programs (such as the one at Curtin University, Australia), and the emerging curricula and courses at a variety of institutions of higher education. It is not yet clear, however, that the current shape of Internet studies will morph into something more recognizable, more traditional, in academia. There is not yet a canon; there are not departments and degrees (Curtin University excepted). There are not yet methods specific to Internet studies. Perhaps most importantly, there is not yet a theoretical structure or exploration of Internet.

Whether there is a field of Internet studies, or whether there is desire or need for a field, is to no small degree a matter out of any one person's control, and may be little more than speculation. For those engaged in Internet studies in an academic setting, it would likely be good to have the institutional imprimatur that comes with recognition as a field. It is important to consider, however, whether there is opportunity for Internet studies to exist, what the circumstances might be under which it may do so, and what shape Internet studies may take and with what consequences.

\section{INTERNET STUDIES AND HISTORY}

In my keynote speech at the Association of Internet Researchers conference in 2003 in Toronto I closed with an exhortation taken from Larry Grossberg's comments about cultural studies in the "Ferment in the Field" issue of the Journal of Communication that Internet studies must be, repurposing Grossberg's words, "driven ... by [our] own sense of history and politics" (1993, p. 89). The practices he identified of cultural studies can also be taken up by those of us practicing Internet studies:

1. "[Be committed $]$ to the fact that reality is continually being made through human action."

2. ' $[\mathrm{Be}]$ continuously drawn to the 'popular,' not as a sociological category purporting to differentiate among cultural practices but as the terrain on which 
people live and political struggle must be carried out in the contemporary world."

3. "[Be committed] to a radical contextualism, a contextualism that precludes defining culture, or the relations between culture and power, outside of the particular context into which [we imagine ourselves] to intervene.... cultural practices cannot be treated as simply texts, as microcosmic representations ... of some social other." (pp. 89-90)

The most important of Grossberg's admonitions to Internet studies is, I believe, the one that calls for "a radical contextualism." There are two important elements to it, of power.

Concerning culture and history, it is necessary for scholars who consider themselves a part of Internet studies, and it is necessary for Internet studies if it is to develop into a field, ${ }^{1}$ to do two things. First, we must understand Internet studies' history in the context of a larger multidisciplinary project to understand the consequences of media and communication. This project has been ongoing primarily since the early part of the 20th century and has engaged scholars in numerous fields, including scientific, social scientific, and humanistic, who have sought to understand the shifts in media and communication since the advent of electronic communication.

If any one thing can hold together Internet studies as a 100 field in the traditional sense, it is that those who profess to be a part of it are engaged in the study of one of the most recent manifestations of a medium for technologically and electronically networked communication. It is important, then, that Internet studies establish the grounds of its history on its own terms, a history encompassing the broader notion of technologically and electronically networked communication. In such a configuration the field of Internet studies would count among its foundational texts not only Internet research or studies of computer-

110 mediated communication, but also, for example, research on the telegraph and telephone, radio (both in its commercial form and its amateur form, including CB radio), and computer bulletin board systems as networked forms of communication.

115 One difficulty is certain to be that research on old media most often leaves us wanting. The various academic fields that have paid attention to media are themselves relatively new. Therefore it is difficult, if not virtually impossible, to find research that takes us to the same period in the 120 evolution of old media as that of the Internet, and we instead are able only to make "apples and oranges" sorts of comparisons. Many of the issues (race and gender, for instance) that drive Internet researchers were unheard of among scholars at the time old media were new. Never- are so often considered, matters of social impact, policy, identity, and economics (to name a few), can be gleaned from studies of telephone, radio and television use from the early to mid-20th century. ${ }^{2}$ Similarly, studies of the diffusion of technology in that era, and in the mid-20th century, 130 such as Kenneth Jackson's The Crabgrass Frontier (1985), can also inform our understanding of the Internet's role in social mobility.

To begin from this base would be not only intellectually fruitful but also a step toward the establishment of a field. If there is a canon to be built it must rest on a foundation built before Internet studies gained currency. Beginning from such a foundation would also be an effort toward establishing an interdisciplinary field. It may also result in a field within which Internet studies is a subfield, a result that $\mathbf{1 4 0}$ may not be optimal for Internet researchers. By broadening our roots we may expose the contours of a larger terrain. Research in technologically and electronically networked communication has a long history in many fields, and has, in one way or another, likely influenced everyone presently $\mathbf{1 4 5}$ doing Internet research. The common threads of inquiry, method, and theory of the precursors to Internet research make up a good place for us to begin to build the vocabularies we need to communicate with one another about our interests, ideas and studies.

But a history of a field is not enough. The history of interdisciplinarity is also an important matter. What might we learn from other nascent fields? The answer to that question is not entirely pleasant. Around the world economic downturns have had significant negative impacts on 155 institutions of higher education. Forces much older than the present economic climate, too, particularly in Western societies' attitudes toward higher education and in the politics of higher education and academe, have been springboards for institutional and curricular (and in some cases ideological) retrenchments. I am sometimes asked whether Internet studies is relevant, given the "dot-com bust" and the recent apparent plateau of Internet adoption in the United States (Madden, 2003). In business schools, programs that flourished during the "dot-com boom" are $\mathbf{1 6 5}$ struggling to retain funding and student interest (Foster, 2004). I generally reply that the consequences of the Internet (social, political, economic, etc.) are too great to ignore and are necessary areas of inquiry and that even if some of the more professional areas of education are struggling they are not likely to vanish. Particularly in the academy, though, the reply is met with skepticism among those who see themselves as upholding traditional academic values in the face of trendy scholarship.

Of greater importance is that the very work of the aca- 175 demic enterprise has of late found itself on shifting sands, as economic gains in the 1990s that led to increases in research funding, formation of centers and institutes, and a general sense of well-being at many, perhaps most, 
180 institutions of higher education in the West have given way to budget cuts, closings, erosion of research and teaching support, and early retirements or layoffs. As Ann Gray noted in an essay on the history of the Birmingham School of Cultural Studies and the Department of Cultural Studies and Sociology at the University of Birmingham, UK:

Those newer, often interdisciplinary, fields that are always in process and never fixed are particularly compromised by these developments. In addition to cultural and media studies, women's and gender studies, ethnic studies, visual cultures, gay and lesbian studies, and post-colonial studies are all ... vulnerable in this climate. (2003, p. 777)

Gray rightly identifies the factors that led to, and the forces that caused, the closure of the department as part of the larger and ongoing effort in the West to commercialize higher education (in the United States illustrated by statements like "higher education should be run like a business," or "the student is a consumer," uttered usually by politicians and functionaries at various levels of government, and all too often by higher education administra-

200 tors). She closes by reflecting on Paul Gilroy's statement that cultural studies has had an influence far greater than a single institution's department, but "whilst cultural studies may no longer need material evidence of its mythic wellspring," the closing of the program at Birmingham "is

205 a loss to the field and a dire warning to us all" (p. 780.) It is also a warning that we may be lured by "the certainties of empiricism," for which Hanno Hardt (1992, p. 76) criticized the fledgling Chicago pragmatists whose work was incorporated into sociology and thereby left out of the

210 early evolution of the field of communication at the point of that field's institutionalization.

I am not convinced that Internet Studies needs either empiricism or "material evidence" of its existence in order to develop intellectually sound scholarship, but I am

215 convinced that without it scholars will be less able to do their work. That is, as scholars we do our work within the material structures and infrastructures of our institutions. The material conditions of our existence, including and particularly those related to the criteria by which academic

220 work (and thus scholars) is judged - criteria increasingly reviewed and critiqued, or worse, revised or established by forces external to the academy-are the sites of struggle for any field, and it is within that context that I wish to consider the other concept related to Grossberg's notion of "radical contextualization": power.

\section{INTERNET STUDIES AND POWER}

There are two notions of "power" most relevant to Internet studies. The first is connected to the place that power has within research. To date, Internet studies has proven relatively adept at welcoming interpretive methods among its tools and theories. However, this is a somewhat cursory and formal welcome. Although there is considerable research that primarily and substantively dwells on matters of language, culture, and meaning, there is less that dwells on matters of power. Quoting James Carey, "Emphasis on 235 language, culture and meaning does not exclude issues of power and conflict; instead, it attempts to locate them" (1997, p. 10).

There are of course studies of conflict online, particularly of flaming and flame wars (though such studies seem $\mathbf{2 4 0}$ to have decreased in number since the mid-1990s). Many of those, however, are descriptive. There should, however, be a foregrounding of matters of power and agency in our research. And it is time that we consider an interpretive turn for Internet studies. This will require, I believe, two $\mathbf{2 4 5}$ actions. One action to be undertaken is questioning by us of how we come to the knowledge we have. That is to say that, if an interpretive turn consists at least in part of self-reflection, of knowing how we know others, then we must as part of the development of our research and schol- 250 arship unpack the complicities and complications of our own positions as Internet users.

The other action is our engagement within our institutions, in their broadest sense (the academic units, nonprofit organizations, scholarly associations, and businesses 255 within which we work), in efforts to explain and promote Internet studies. It is not inappropriate, nor is it too "early" in the growth of Internet studies, to simply ask ourselves what we are up to, and to make our answer clear to the variety of constituent groups with which we interact. A $\mathbf{2 6 0}$ hermeneutics of Internet studies would serve us well at a time when there seems to be much discussion of method. Perhaps, in fact, the degree to which we are engaging ourselves in searches for methodologies appropriate (or in some cases unique) to Internet studies is a sign that we are $\mathbf{2 6 5}$ becoming caught up in the notion that there is a "truth" about the Internet that may be ascertained by the careful adherence to methodological principles. There is much to the notion, I think, that the Internet shows us what we want it to be, and much to the obverse notion, that what $\mathbf{2 7 0}$ we want the Internet to be shows through in our research and scholarship.

It is appropriate and necessary to discuss what the consequences of our work may be for those people and technologies we study. In some of our work we may be ac- 275 tivists, and in other work we may seek to be unobtrusive. In either case, and in the case of those between the extremes, while we can guard against consequences, we cannot necessarily prevent them. Yet we can incorporate notions of significant involvement and functional relevance (Bowman, 1991) into our work. And we ought to also consider what happens to us as we do our work and interact with the people and technology we study. For us to not do so is not only an abrogation of power but also a fundamentally irresponsible and unethical act. 
By way of example, I offer that in the vast majority of times power is addressed in Internet research it enters through the back door via the notion of access. This is most commonly the case in numerous studies of the dig-

290 ital divide. But access is only one of the ways in which power can manifest. In matters of language, code, policy, and regulation, one can find power relations. Virtually every mode of online communication has embedded within it power relations, and online communities, too, are not

295 neutral areas of connection among others. Following Foucault's statement that "power relations are rooted deep in the social nexus, not reconstituted 'above' society as a supplementary structure whose radical effacement one could perhaps dream of" (1982, p. 208), it is reasonable to claim

300 that power relations are rooted deep in the Internet, not only reconstituted in text or discourse (though often actualized there), and that they are connected in turn to power relations offline, in ways that are difficult, if not impossible, to understand and analyze if one's gaze is turned to the Internet only.

The second notion of power that arises from radical contextualization is itself linked to the contexts within which we work, contexts that I have already discussed in regard to our institutions. Seen through the lens of power, how-

310 ever, there are more things to say, particularly as it is in this realm that the consequences for Internet studies as an institutionalized academic field are greatest.

Questions of power, institutionally speaking, fall into two categories: hierarchical and personal. The former con-

315 cerns our options at agency within our institutions under the circumstances of political roles, structures, and authority. The latter concerns efforts to link our research and scholarship to the former.

When it comes to the hierarchical structures of power

320 within our institutions, it may be appropriate to ask now only whether we need or want an Internet studies but what it may look like. Is it best to tread the traditional route, to grow from a gathering of scholars to a field, then a discipline, to move from center or institute to department 325 and school and college? Perhaps there are alternatives. Perhaps we should be careful what we wish for.

It is also important to ask whether now is the time for us to pursue its development. There are presently several barriers to the development of Internet studies. One is that our universities, particularly in the United States, are well populated with centers for this-that-and-the-other studies, and in a time of financial exigency are not likely to add more such units. That means we will need to find our own opportunities for funding. But those are not likely to come

335 from other than commercial sources, and as scholars we do not yet hold the upper hand. It should be noted that the first "Center for Internet Studies" that Google shows when searching using the keywords "Internet" and "studies" is a for-profit venture, at www.virtual-addiction.com, "a business dedicated to providing services, information, 340 and resources on e-behavior and Internet addiction in the workplace, our families and in the community."

The preceding discussion makes it seem, however, that our own group agency is greater than it likely is. Instead it will likely be up to individuals with energy and vision $\mathbf{3 4 5}$ to pursue the building of the structures of a field. And it is in the realm of the individual, of personal power, that our greatest challenges lay. The call for contributors to the 1993 Journal of Communication "Ferment in the Field" issue was to write "on the state of communications research $\mathbf{3 5 0}$ today: the relationship of the research with respect to social issues and social structure; and the tactics and strategies for reaching their goals." We are making progress on so doing, but I suspect we are making more progress among ourselves and less progress within our disciplines and aca- 355 demic units. Further, as long as we are members of disciplinary units (be they academic departments, scholarly associations, etc.), we must both attend to the exercise of power within their structures and attend to our own power and exercise it where appropriate. This means that it is $\mathbf{3 6 0}$ required of us to participate in governance and administration, to consider the need for leadership and heed its call, and to no small degree to question the values embedded in the structures within which power is exercised. In short, we must play an active role in critiquing and establishing 365 what "counts" within the contexts within which we work, and we must grapple with its shifting nature.

As to our scholarship, it would behoove us to look at some of the important work on the cultural shifts brought about by old technologies as models for future work. The $\mathbf{3 7 0}$ rhetoric of a "dot-com" or Internet revolution has largely receded from the popular landscape, but the evolution of the Internet in society continues apace, and with it continue changes in social and economic patterns. It would be of benefit to return to some of the work that examined 375 the major shifts in communication, such as those from oral to print culture (Eisenstein, 1980; Goody, 1986; Hoggart, 1957; Innis, 1951, 1995; Ong, 1982), for instance, as it could serve, if nothing else, to remind us that even though we may not yet have the distance from our own time to $\mathbf{3 8 0}$ clearly perceive the situation, Internet studies can, to again borrow from Grossberg (1989, p. 415), describe and intervene in the life and values of the people who use the Internet, and that these can best be understood, no matter our temporal distance, through close observation and analysis $\mathbf{3 8 5}$ of specific people and technologies, in specific places and times.

\section{NOTES}

1. I consider these to be two separate things, namely, that scholars $\mathbf{3 9 0}$ can consider themselves part of Internet studies even if there is no acknowledgment or existence of a field. 
2. See, for example, Carolyn Marvin's When Old Technologies Were New (1988) and the work of James W. Carey (1989), particularly on 395 the telegraph's impact in the United States, and Brian Winston's Media Technology and Society (1998).

\section{REFERENCES}

Bowman, P. J. 191. Race, class and ethics in research: Belmont principles to functional relevance. In Black psychology, eds. R. L. Jones,

400 pp. 747-766. Berkeley, CA: Cobbs \& Henry.

Carey, J. W. 1989. Communication as culture: Essays on media and society. Boston: Unwin Hyman.

Carey, J. W. 1997. Reflections on the project of (American) cultural studies. In Cultural studies in question, eds. M. Ferguson, and $\mathrm{P}$. Golding, pp. 1-24. Thousand Oaks, CA: Sage.

Eisenstein, E. L. 1980. The printing press as an agent of change: Communications and cultural transformations in early-modern Europe. Cambridge: Cambridge University Press.

Foster, A. L. 2004, February 20. Is the party over for e-commerce courses? Chronicle of Higher Education, pp. A29-A30.

Foucault, M. 1982. Michel Foucault: Beyond structuralism and hermeneutics. Chicago: University of Chicago Press.

Goody, J. 1986. The logic of writing and the organization of society. Cambridge University Press.

415 Gray. A. 2003. Cultural studies at Birmingham: The impossibility of critical pedagogy? Cultural Studies 17(6):767-782.
Grossberg, L. 1989. The circulation of cultural studies. Critical Studies in Mass Communication 6(4):413-421.

Grossberg, L. 1993. Can cultural studies find true happiness in communication? Journal of Communication 43(3):8997.

Hardt, H. 1992. Critical communication studies: Communication, history and theory in America. New York: Routledge.

Hoggart, R. 1957. The uses of literacy: Aspects of working-class life. London: Chatto \& Windus.

Innis, H. A. 1951. The bias of communication. Toronto: University of Toronto Press.

Innis, H. A. 1995. Staples, markets, and cultural change. Montreal: McGill-Queen's University Press.

Jackson, K. T. 1985. Crabgrass frontier: The suburbanization of the United States. New York: Oxford University Press.

Madden, Mary. 2003. America's online pursuits: The changing picture of who's online and what they do. Washington, DC: Pew Internet \& American Life Project. http://www.pewInternet.org/reports/ pdfs/PIP_Online_Pursuits_Final.pdf (accessed March 2, 2004).

Marvin, C. 1988. When old technologies were new: Thinking about 435 electric communication in the late nineteenth century. New York: Oxford University Press.

Ong, W. J. 1982. Orality and literacy: The technologizing of the word. London: Methuen.

Winston, B. 1998. Media technology and society: A history from the 440 telegraph to the Internet. London: Routledge. 